\title{
Talking with Teachers, Administrators, and Parents: Preferences for Visual Displays of Education Data
}

\author{
Charlotte Y. Alverson \& Scott H. Yamamoto \\ University of Oregon, United States \\ Correspondence: Charlotte Y. Alverson, Research Associate in Secondary Special Education and Transition, \\ University of Oregon, United States
}

Received: October 25, 2013 Accepted: November 13, 2013 Online Published: January 24, 2014

doi:10.11114/jets.v2i2.253

URL: http://dx.doi.org/10.11114/jets.v2i2.253

\begin{abstract}
The purpose of this study was to learn from educational stakeholders what characteristics they like and dislike when viewing graphs of post-school outcomes data. We conducted six, 1-hour focus groups with teachers, administrators, and parents in which we distributed four stimuli graphs - horizontal grouped bars, horizontal stacked bars, vertical stacked columns, and vertical grouped columns - to solicit participants' preferences for data displayed graphically. Our findings indicate that multiple factors contributed to participants' stated preferences for one graphic display over another. These factors include ease of understanding information displayed in the graph, familiarity with the display, comfort, as well as speed and habit for administrators. We discuss implications for practitioners, identify areas for further research, and recommend considerations when designing graphs for educational stakeholders.
\end{abstract}

Keywords: data displays, graphic displays, visual data displays

\section{Introduction}

\subsection{Need for Data Displays that Facilitate, rather than Hinder, Data-driven Decision Making}

Using data to improve in-school programming and student performance is expected of $21^{\text {st }}$ century state and local educational leaders. Administrators, teachers, and parents are expected to use a variety of data to drive program improvement. For special education administrators, teachers, and parents, these data include post-school outcomes (PSO) data of former secondary students to improve in-school transition programs. The 2004 reauthorization of the Individuals with Disabilities Education Improvement Act (IDEA) requires state education agencies (SEA) to examine the further education and employment experiences of former students. The need for this data-collection effort is based on one purpose of IDEA:

"To ensure that all children with disabilities have available to them a free appropriate public education that emphasizes special education and related services designed to meet their unique needs and prepare them for further education, employment, and independent living..." (34 CFR §300.1(a)).

Whether a state has met the IDEA requirements is measured, in part, by the extent to which former students with disabilities were enrolled in higher education, postsecondary school or training, and/or working during the year after leaving school. With input from teachers, parents, and administrators (i.e., stakeholders), state departments of education in the United States are expected to use PSO data collected from former students when setting rigorous and measurable targets to increase these outcomes and identify and implement improvement activities designed to reach the targets. Setting targets and identifying improvement activities require stakeholders to engage in conversations about PSO data. Decisions resulting from the conversations have the potential to generate change at all levels of the education system.

Significant change in the educational system, however, can occur only when stakeholders use data to drive change. If change based on data is to occur in a meaningful way, stakeholders must understand and be comfortable engaging in conversations about data. Understanding what diverse audiences need to interpret and use data is essential for developing data displays that facilitate, rather than hinder, data-driven decision making. Therefore, the intent of this study was to examine stakeholder preferences for visual data displays of PSO data.

To be a change catalyst, PSO data must first be valid and reliable at federal and state levels, and second, relevant and meaningful at the individual district and school levels. Moreover, as a basis for decision making, stakeholders at all 
levels must be comfortable reviewing and discussing data. That is to say, PSO data must be accessible and useable for parents, teachers, principals, and other school administrators.

\subsection{Accessible and Useable Data}

Carnine (1997) defines accessibility as "... the ease and quickness with which practitioners can obtain research findings and extract the necessary information related to a certain goal..." (p. 363). Furthermore, he defines usability as "... the likelihood that the research will be used by those who have the responsibility for making decisions..." (Carnine, 1997, p. 363). For decades, state educational institutions have collected and stored student-related data (Wayman, 2005), yet schools are often described as being data-rich and information poor (Wayman \& Stringfield, 2006; Wayman, 2005). Large quantities of data are not readily accessible to most education agencies in a format that enables usability to inform district or school policy or decision-making processes. Barriers to using these data include antiquated technologies (Wayman \& Stringfield, 2006), lack of time for mining data and interpreting the findings (Kowalski \& Lasley, 2009), and a general lack of technical expertise (Earl \& Katz, 2006; Kowalski \& Lasley, 2009).

Researchers have speculated that the availability of user-friendly technologies will increase access to and use of data for decision-making purposes (e.g., Earl \& Katz, 2006; Wayman, 2005; Wayman \& Stringfield, 2006). Earlier researchers (e.g., Henry, 1997; Schmid, 1954, 1983; Wainer, 1984, 1997b) focused less on medium and technological enhancements and more on various visual data displays options, such as graphs, for increasing accessibility and usability of data for decision making.

\subsection{Data Displays for Education}

Prior to the assessment and reporting requirements of No Child Left Behind (NCLB) and IDEA, results of the National Assessment of Educational Progress (NAEP) were reported to various audiences. These data were intended to inform policymakers, educators, and the public about students' achievement and monitor achievement changes over time (Hambleton \& Slater, 1996). In the late 1990s, researchers (e.g., Hambleton \& Slater, 1994, 1996; Wainer, 1996, 1997a, 1997b; Wainer, Hambleton \& Meara, 1999) began investigating alternative displays for presenting NAEP results to educational audiences. Hambleton and Slater (1994) asserted that educational audiences reading the NAEP results "... are not well prepared to handle the wealth of data that a complex NAEP assessment provides" (p. 2), and suggested that a "...threat to the validity of inferences about NAEP results... [is]...due to the misunderstanding of the NAEP reports themselves by intended NAEP audiences" (p. 2). They attributed misunderstandings to three possible factors: (a) brief and or confusing text, (b) complex tables and displays that were difficult to read, and (c) characteristics of tables and figures.

Hambleton and Slater (1996) emphasized the importance of considering how scores are reported in order to reduce confusion and misinterpretations and ensure that the intended interpretations are made. Asserting that properly designed figures and tables can convey substantial amounts of data clearly, efficiently and effectively, they defined properly designed as figures and tables that "... are clear to the audiences for whom they are intended" (p. 19). The visual characteristics that make a graph clear to an intended audience are unknown.

Previous research identified an audience's lack of familiarity with a chart as a common theme when looking at graphs displaying NAEP results. Hambleton and Slater (1996) found educators and education policymakers wanted an explanation of the graphs displaying the NAEP results in order to understand what the graphs represented. In interviews with education administrators and teachers from five school districts reviewing PSO data, Johnson (2000) found educational audiences wanted the data presented visually and explained verbally. These audiences acknowledged they would not have spent time reviewing the information represented in the graphs if someone had not reviewed the data with them.

\subsection{Empirical Research of Data Display}

In the field of education, empirical research related to data display has typically focused on curricular content for teaching graph design (Friel, Curcio, \& Bright, 2001; McClure, 1998; Shah \& Hoeffner, 2002, p. 341); graphicacy (i.e., the ability to read graphs) (Friel \& Bright, 1996; Wainer, 1980); or presentation of large scale, multivariate results (e.g., $4^{\text {th }}$ graders' reading and math scores from the NAEP) to a variety of educational audiences (Hambleton \& Slater, 1994, 1996; Wainer, 1996b, 1997a, 1997b). In the field of education, empirical literature is limited regarding data displayed to engage teachers, administrators, and parents in conversations that culminate in programmatic change and improved student outcomes. The need to train teachers and administrators in data interpretation and use is a recurring theme in recent educational literature (e.g., Archer, 2005; Kerr, Marsh, Ikemoto, Darilek \& Barney, 2006; Wayman, 2005; Young, 2006). Wayman (2005) asserts, "The mere presence of data does not automatically imply that useable information is available; educators need support to use these data to the fullest extent" (p. 296). The purpose of this study was to learn from educational stakeholders what characteristics they like and dislike when viewing graphs of PSO 
data. It was guided by the research question: What preferences, if any, do teachers, education administrators, and parents have for graphically-displayed data?

\section{Method}

\subsection{Design}

We conducted six focus groups in a Northwestern state. We chose this method for two reasons. First, there is a glaring lack of empirical research about people's preferences for graphical presentations of data. Second, we believed it was important to have individual educational stakeholders articulate, in as full and rich detail as time would allow, the specific characteristics of a graph they liked or disliked and why. Next, we describe the (a) research participants, including recruiting procedures and characteristics of the focus groups, (b) data collection techniques, and (c) analysis.

\subsection{Focus Group Participants}

\subsubsection{Teachers}

Teachers were certified classroom staff currently employed in a high school setting or graduate students in a preparation program to become certified teachers. Special education teachers, either practicing or in preparation, were purposefully recruited because our research study pertained to PSO data of students with disabilities and these data are most relevant for these teachers. We recruited teacher participants from a state conference for practicing special educators by distributing flyers throughout the conference. Graduate students were recruited from a transitions-focused special-education course for Middle-High Licensure program. In total, 12 practicing or pre-service teachers participated in two focus groups.

\subsubsection{Administrators}

Administrators were defined as individuals responsible for program supervision, development, and or evaluation. We purposefully recruited participants for the administrators' focus group from a local education agency (LEA) and state education agencies (SEA) from across the nation. We recruited LEA administrators by contacting the special education director for an urban educational service district and requesting a list of school special education administrators. Letters inviting them to participate were then sent to school and central office administrators explaining the purpose, time, and location for the focus group. SEA administrators were personnel at the state department of education responsible for the collection, analysis, reporting, or use of state level accountability data. This group included state special education directors, data managers, and state transition specialists. We compiled an initial list of state administrators from contacts maintained by a national technical assistance center, then verified and supplemented the list from information posted on states' websites. Recruitment letters were sent to 70 SEA administrators describing the study, along with a schedule of teleconferences and call-in information. We held teleconferences with SEA personnel from across the nation and one, in-person focus group with personnel from an SEA. In total, 12 LEA and SEA administrators participated in the focus groups.

\subsubsection{Parents}

Parent participants in the focus groups included natural, stepparent, or guardian of a child with a disability who were members of a parent advocacy group. Parents were purposefully recruited from state advocacy organizations because they frequently serve as stakeholders participating in the decision-making processes relevant to children with disabilities. We emailed recruitment materials to six regional parent representatives across the state. Regional representatives were asked to forward the letter to their local district and county leaders, who were asked to contact the lead author of this study if they were willing to host a focus group in their area. Local leaders were asked to share the recruitment flier with parents of school-aged children with disabilities. Interested parents were asked to call the authors. When we spoke to interested parents, we confirmed that they had a child with a disability, answered questions about the study, and invited them to participate. The parent focus groups were held in rural and urban areas, approximately 300 miles apart. In total, five parents participated in two focus groups.

\subsection{Focus Group Data Collection}

Representatives from the three educational stakeholder audiences participated in separate focus groups designed as conversations (see Stewart, Shamdasani, \& Rook, 2007) to solicit their preferences for data displays. Next, we describe the procedures and graph stimuli.

\subsubsection{Focus Group Procedures}

We used a structured interview protocol containing nine open-ended questions and follow-up prompts to guide the conversations. To develop the protocol, an initial set of questions were pretested with a small group (see Stewart, Shamdasani, \& Rook, 2007) of parents and teachers to ensure the questions generated the desired conversation. Based on feedback, we reworded awkward questions and eliminated duplicate questions. At the start of each in-person focus 
group, we described the purpose of the study, obtained consent for participation, and answered study related questions. For the teleconference focus groups, the facilitator described the study purpose, process for activities, and answered questions prior to obtaining verbal consent to participate. The four graph stimuli were emailed to participants and then we began the interview questions. The teleconference focus groups were attended by state department directors of special education and transition consultants from across the nation. All focus groups were audio recorded and transcribed verbatim by a professional transcriptionist.

\subsubsection{Graph Stimuli}

To solicit participants' preferences for data displayed graphically, we distributed four stimuli graphs-horizontal grouped bars (Figure 1), horizontal stacked bars (Figure 2), vertical stacked columns (Figure 3), and vertical grouped columns (Figure 4). Each graph was printed in black, gray, and white on 8.5" x 11 " white paper in landscape orientation. An Excel (Microsoft, 2003) worksheet was used to create the stimuli graphs containing the post-school outcomes of working, in school, and both (i.e., working and going to school) for two demographic categories - type of disability and gender. We chose the context of PSO data for this study due to the requirement for states to collect and report PSO, and therefore, making these data more available in states. Of the four graphs, three displayed the PSO data disaggregated by four types of disabilities plus an All Youth from the State category and contained 15 data points. The fourth graph, PSO data by gender, contained nine data points.

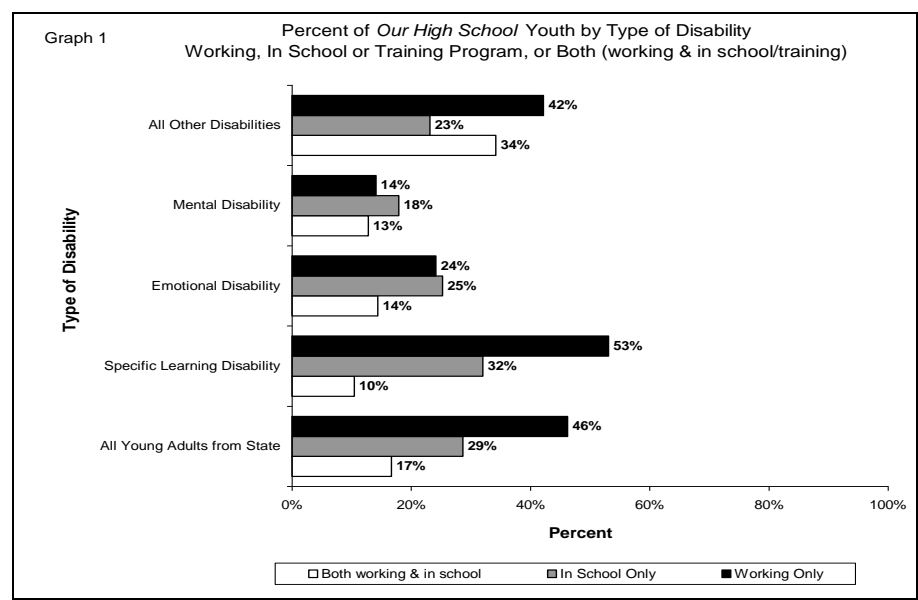

Figure 1. Horizontal Grouped Bars

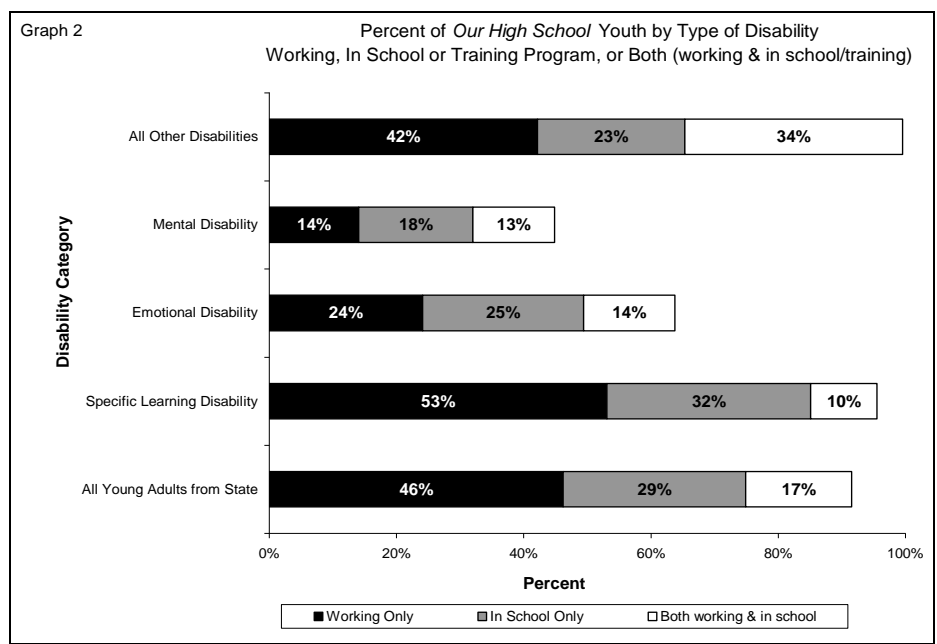

Figure 2. Horizontal Stacked Bars 


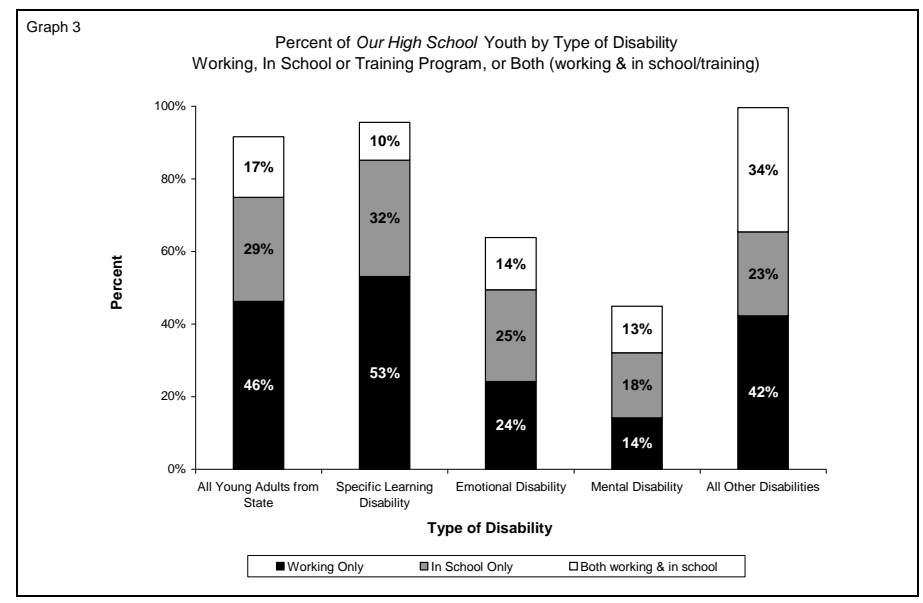

Figure 3. Vertical Stacked Columns

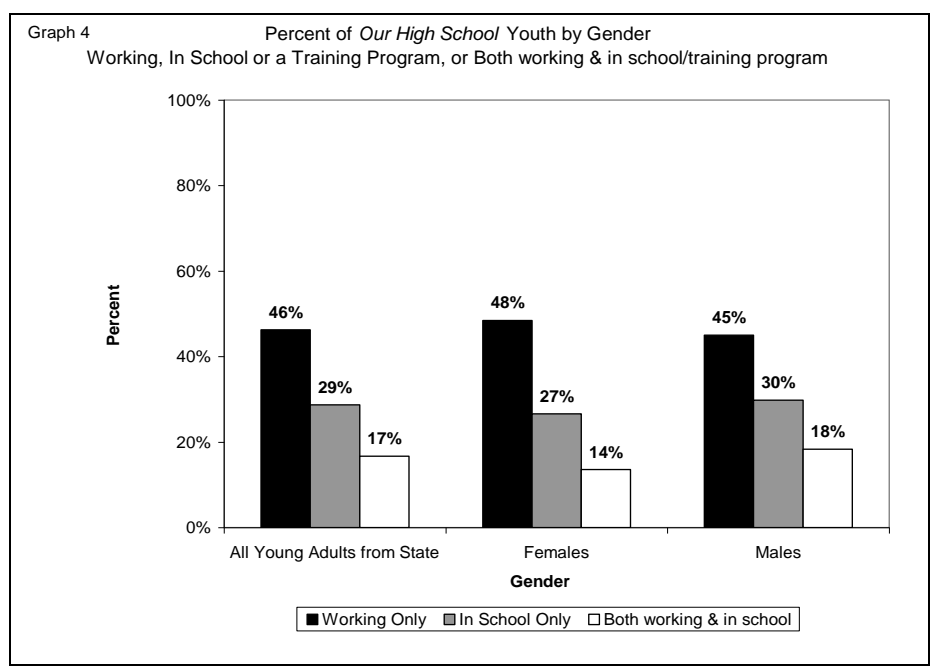

Figure 4. Vertical Grouped Columns

\subsection{Focus Group Data Analysis}

Each transcript was read while listening to the audio file to ensure accuracy in transcription and note voice tone, inflection, and other subtleties that may have been missed by the transcriptionist. To analyze the focus-group data, we used the interview protocol as an initial organizer to create a start list of codes (Miles and Huberman, 1994). Start list codes were (a) defining the term data, (b) experience with data, (c) data use, (d) time, and (e) how data are shared currently by the school district. While coding the first three transcripts, emergent themes were noted. We refined the coding scheme to include additional general (i.e., etic) level codes and more specific codes (i.e., emic) nested within the general categories (Miles \& Huberman, 1994). Emic codes captured examples and elaborations relevant to the general code. Emergent themes added to the coding scheme were (a) accuracy, (b) purpose or message of the graph, (c) audience for the graph, (d) graph characteristics, and (e) graph specific comments.

All focus group transcripts were coded using the coding scheme in Table 1. Using the qualitative software program NUD*IST-6 (N6, 2002), we assigned a code to phrases of the transcript. The coded phrases were extracted from the transcripts and organized by code, resulting in node reports. Node reports were examined for themes relevant to preferences within and across the different stakeholder audiences. From patterns and themes identified in the node reports, we developed an interim report outlining similarities and differences across cases relative to preferences educational audiences have for graphical displays of data.

Table 1. Transcript Codes 


\begin{tabular}{ll}
\hline Code & Code Definition \\
\hline defining data & how individuals define the word data and make associations with data \\
experience with data & how individuals interact with data or use data; mistrust of data; examples of personal \\
& experiences with data \\
how data are used; expectations for use, examples of comparisons and summarizations based & on data \\
data use & how long individuals look at a graph; how long they expect to look at a graph; frequency of \\
using data to make a decision & methods used by school or state department of education to share data with various \\
time & stakeholders; how individuals currently see data displayed \\
how data are currently & individual's preference for graph type, what they like and don't like about data or graphs; \\
shared & statement in favor of or opposed to specific graph characteristic \\
preference & how accurate individuals report to be or how accurate they think they are; understanding of \\
data & type of information school or state department of education share with stakeholders; what \\
individuals perceived to be the intended message & who data are intended for or used with \\
purpose or message & grid lines, legend, amount of information in the graph, box or frame on graph, graph title \\
comments comparing two or more specific graphs; comments about a specific graph
\end{tabular}

\section{Results}

The research question for this study was: What preferences, if any, do teachers, education administrators, and parents have for graphically-displayed data? To answer this question, we conducted focus groups with teachers, administrators, and parents. Through qualitative coding of the focus groups, we identified emergent themes related to the preferences of teachers, administrators, and parents. Next, we describe the characteristics of the focus groups, followed by findings specific to the preferences of each educational audience.

\subsection{Characteristics of Focus Groups}

A total of 29 individuals participated in 1-hour focus groups. Demographic information for each audience is presented in Table 2. Across the audiences, $72 \%$ of participants were female. Administrators reported being in their current position from 2 to 24 years $(M=12, S D=7.55)$, approximately four times longer than teachers. Teachers reported being in their current position from 1 to 12 years $(M=2.79, S D=3.27)$; one-half reportedly in their first year of teaching. Parents reported being a member of the advocacy group for 1 or 2 years $(M=1.80, S D=.45)$. The majority of administrators $(n=10)$ had a master's degree or higher; one-fourth $(\mathrm{n}=3)$ of the teachers had a master's degree. The highest level of education obtained by parents was some college by one parent. All other parents had completed high school or the GED. Parents' oldest child with a disability ranged in ages from 8 to 16 years.

Table 2. Demographics of Focus Group Participants

\begin{tabular}{lccc}
\hline & \multicolumn{3}{c}{ Audience } \\
\cline { 2 - 4 } & Teachers & Administrators & Parents \\
& $\mathrm{N}=12$ & $\mathrm{~N}=12$ & $\mathrm{~N}=5$ \\
\cline { 2 - 4 } Females & 7 & 10 & 4 \\
Range of years in current position & $1-12$ & $2-24^{*}$ & $1-2$ \\
Level of education: & & & 4 \\
High School Diploma/GED & & 2 & 1 \\
Some college & 9 & 8 & \\
Bachelor's 's degree & 3 & 2 & $8-16$ yrs. \\
Master's degree & & & \\
Doctorate degree & & & \\
Age of oldest child with a disability & & & \\
\hline
\end{tabular}

Note. * based on 10 responses to this question.

3.2 Preferences of Educational Audiences 
Table 3 displays the themes that emerged across the three audiences as they described why they preferred one graph over the others. Preferences of each audience are described next.

Table 3. Emergent Themes by audience

\begin{tabular}{lccc}
\hline & Teachers & Administrators & Parents \\
\cline { 2 - 4 } Ease, easy & $\mathrm{X}$ & $\mathrm{X}$ & $\mathrm{X}$ \\
Familiarity & $\mathrm{X}$ & & $\mathrm{X}$ \\
Comfort & $\mathrm{X}$ & $\mathrm{X}$ & \\
Speed & & $\mathrm{X}$ & \\
Habit & & $\mathrm{X}$ & \\
\hline
\end{tabular}

\subsubsection{Teachers}

As teachers discussed the four types of graphs, they identified a clear preference for the grouped column graph (Figure 4), over either horizontal graphs (Figures 1 and 2) or the stacked column graph (Figure 3). Teachers frequently used the terms easy, familiarity, and comfort to describe why they preferred the grouped column graph. They described the ease with which they could make comparisons across groups and see differences between the groups when viewing the grouped column graph. They attributed the ease of seeing patterns in the data to their familiarity with the grouped columns graph. Teachers reported using and seeing grouped columns graphs frequently, therefore they were comfortable reading this type of graph. Moreover, they associated familiarity and comfort viewing grouped columns with a willingness to invest time in trying to understand the data. Teachers consistently identified stacked graphs, whether horizontal or vertical, as the graphs they did not like. Recurring themes referenced lack of familiarity with these graphs, and difficulty understanding what the graph represented. Teachers discussed their uncertainty regarding what to attend to in a stacked graph, questioning whether they should focus on the overall total, as represented by the height of the column or length of the bar, or focus on making comparisons across groups, as represented by individual segments on a bar or column. One teacher stated, "I have trouble with this one [pointing to the stacked bars as seen in Figure 3 (field notes)] in the sense that it's easy to compare all of the black bars against each other, but it's harder to compare all of the gray bars next to each other because they're not justified, you know what I mean? It's the same with the white [segments]. It's all there, I mean the information is all there, but I can't just glance at it and boom, I can just look at it and line up the gray [segments]..." (Teachers1, lines $584-590$ ). Teachers admitted to not trying to make comparisons across the segments of a stacked column, and instead, drew conclusions based only on the column height when viewing a stacked column graph.

\subsubsection{Administrators}

State and local administrators also had a clear preference for the grouped columns graphs, with one clear exception. Administrators preferred stacked columns when given the choice between multiple graphs of grouped columns, each on a separate page, or a single graph displaying the same information. These administrators preferred one graph with a lot of information to having pages of multiple graphs that, they admitted, would be easier to understand. From the administrators' focus group, emergent themes included (a) ease, (b) comfort, (c) speed, and (d) habit.

Like teachers, the administrators often talked about the ease and comfort with which they could quickly glean information from the grouped column graph. Administrators in all of the focus groups repeatedly commented on how easily they could look across the grouped columns (Figure 4) and quickly make an interpretation. They explained the more comfortable they were with the display, the easier it was for them to understand the information. A local administrator's comment is representative, "It's just-quickly looking across, you can see the differences...it's just easier and I can catch it at a glance" (local administrators, lines 202 and 206). A reference to ease or comfort also frequently included a reference to the speed or how quickly they could extract information or find meaning in a grouped graph. One state administrator's comment, also referencing the grouped columns graph, represents well the discussion related to the speed with which they viewed the graph, "I think it's cleaner. It's, for some reason, just the up and down kind of chart is visually easier for me to interpret real quickly than the other ones" (State administrators2, lines 169-171).

Another emergent theme from the conversation with administrators had to do with habit; specifically, the habit of relying upon a particular type of graph when they needed to create a graph. When describing her use of graphs, and particularly her responsibility for creating graphs for others, one district level administrator admitted to not giving much thought to the type of data displayed or the audience when choosing a graph for a presentation. Pointing to the grouped columns graph, she stated, "I've never really thought about it that much but this is usually what I do" (local administrators, lines 312 - 313). Other administrators concurred, while several other participants simultaneously commented, "it's just a habit, you know, ...routine..., yeah, routine you know, ....it's [creating graphs for reports]a 
normal part of what we do every day and we don't stop to think about it..." (local administrators, lines 322 - 325). As SEA administrators described how they typically selected the type of graph for presentations, one stated, "I don't think people think about it [the type of graph that should be used]. They rely on the default settings on the computer to pick the display or plop in the numbers from a graph that was used previously and they have a graph; just because that's what they've always done." (State administrators4, lines 214 -216). This administrator's comment drew a quick and emphatic, "I couldn't disagree more!" (State administrators4, line 217), from a colleague sitting across the table. The dissenting colleague described her responsibility for developing the state report card for No Child Left Behind (NCLB) and the elaborate process she used to determine which graphs to include in the annual state report card distributed to schools and families. She described testing different graphs with people in the office to determine "...the best graph [to use]..." (State administrators4, line 222) based on the data being displayed. She also stated she always considers audience and message when developing graphs. She viewed using the same graph type with the same audience yearly as a matter of consistency, not a habit.

In their conversations about data displays, administrators were vocal about their dislike for stacked bars or columns and two primary reasons emerged. First, they disliked the uneven axes and second, they frequently referred to their general lack of comfort and familiarity with these types of graphs. When talking about stacked bars and columns, administrators described their dislike for graphs with uneven axes. "[By] not having a common axis against the second and third categories there, if I wanted to look at In School only, I wouldn't be able to...it's not as easy to see the relative proportions because they don't start at the bottom' (State administrators3, lines 214-219). Like teachers, several administrators described looking at the overall results displayed in a stacked graph, represented in the cumulative percent, and not trying to identify discrepancies between groups, represented in the individual segments of the stacked column or bar. For one administrator, she explained that the stacked columns and bars were her least favorite graph type because she first had to understand how to use the stacked graphs before she could determine what information the graph represented.

The lack of comfort and familiarity emerged as a second theme when administrators discussed their dislike for horizontal bars. "I'm just not accustomed to reading graphs horizontally" (State administrators3, line 168). “...I don't relate too well to horizontal ones, so when I look at it, I have to turn it to the side, 90 degrees, so I can see it up and down.... find it difficult to just quickly pick up on the data...it is just not comfortable for me visually" (State administrators3, lines 203 - 209). Other SEA administrators concurred. One local administrator asserted not having enough time to understand the stacked bars, saying, "Just tell me what I'm supposed to know from this [horizontal stacked bars]; I prefer to be told. I don't have enough time to discover a lot (Local administrator, lines 125 - 126). Having time to examine graphs was also mentioned by state administrators as a barrier to their using graphs when presenting data at stakeholder meetings. "You don't have that much time to spend for the audience looking at the graph" (State administrators3, line 74). "It's too much information if you expect someone to look at them quickly" (State administrators3, lines 80). Another administrator added, "These [Figures 1 and 4] are more than 2 or 3 minutes, these [Figures 2 and 3] are 3-10 minutes. If you're doing a presentation, it generally needs to be 1 minute for people to get information, I think." (State administrators3, lines $84-85$ ).

\subsubsection{Parents}

Parents expressed a clear preference for grouped columns. Similar to teachers and administrators, parents' familiarity with a particular type of graph and ease in understanding the information influenced their preference. Parents related their familiarity with grouped columns to their experiences with graphs when they were students or graphs they encounter in their daily lives. "Well it's more forthright. Don't you think [showing the grouped columns to a parent across the table]...isn't it this one, that you know, of any one that you have seen in school, these are the ones that we used, right? To which the other parent responded, "This is the one that sticks out, yeah, this is the one that stands out" (parent1, lines $71-75$ ). One parent described being most familiar with the grouped columns because she sees them on the monthly utility bill. By seeing the graph frequently, she felt comfortable interpreting the information; she did not have to learn how to read the graphs, explaining, "It's easy to read because I'm used to it" (parent1, lines 249-250). Parents associated the ease of reading grouped columns (Figure 4) with the simplicity of the graph. "It's to the point. It's quick and to the point. You got everything right there...; I would take a moment to look at this because of the way it is presented" (parents2, lines 132 - 135). Referring to the graphs distributed in the focus group, one parent said, "Now this one [pointing to the grouped columns], this one I would look at. I would try to figure out what it was saying" (parents2, lines $119-120$ ).

Parents indicated that the type of graph would influence whether they took the time to review the information. One parent reported he would not take the time to look at stacked graphs if they were the first ones he saw in a report. In addition to not liking the stacked columns, he explained he did not like monochromatic graphs, "because in black and white, you're looking at it and you know, the gray kind of blends in with the black and the white kind of blends in with 
the gray and you just did 8 hour of work, 2 hours of fighting with the kids and the last thing you want to do with your last hour is look at a black and white piece of paper. It's got to get my attention" (parent1, lines 314-318). Other parents concurred, emphasizing that in order for them to spend time looking at graphs, the graphs would need to get their attention immediately.

As parents discussed what they did not like about graphs, difficulty understanding stacked columns emerged as the predominant theme. Parents commented, "this one [pointing to the stacked columns] is really hard for me (parents2, line 30), and "I don't understand that one", again, pointing to the stacked column (parents1, line 109). Parents described not being able to easily make comparisons across the groups when looking at information in the stacked graphs. As one parent expressed, "if you're trying to do some comparisons, it's really complicated. What do I look at?" (parents2, lines 119 -120). When asked how much time he would spend studying the stacked columns, one parent quickly replied, "I wouldn' ' $t$ " (parents2, line 123); a comment echoed by other parents. Asked how much time they would spend looking a graph of horizontal grouped bars, many parents agreed they would glance at horizontal graphs but considered the stacked bars and columns a “...waste of time" parents2, line 129).

A theme unique to the parent focus groups and somewhat tangential to their preference for data displays was their desire to have information that pertained to their child and his or her school. Across both focus groups, parents emphasized their desire to have information about their local school and the programs that affected their child. Parents repeatedly expressed a desire for "... simply having any information..." (parents1, line 126) about their child and their child's school. Asked if they wanted only local information or the statewide data as well, one parent responded, "I like to know how my child is doing right here, because that way, I have better control of what to say to help him be better at what he's doing here, compared to, like, I don't know what that kid is doing in [another city]; ... maybe what I decide may not be good for that child in [another city]" (parent2, lines 182 -186). Parents in both focus groups described a frustration with the lack of information on children with disabilities, "There isn't a lot. It seems like a lot of the information we're looking at, there aren't a lot of graphs for our kids so you can't compare overall (parent1, lines 94 96). A sentiment echoed by another parent, "Right. When I was looking at our last report card, I was trying to figure out where our kids were at and it just said, 20\%, or whatever the percentage is... of what? What is it compared to? I couldn't find any [explanations]" (parents1, lines 98 - 100). In general, parents first wanted information relevant to their children and school, and then statewide data second. The more relevant the information was to their children the more willing parents were to invest time and effort trying to understand the information, regardless of the data display. All the parents expressed a willingness to serve on committees using data to make program decisions, and most acknowledged that they would need time to review the data and understand what was being presented. One parent said, “...don't throw numbers at me .... I think just make it as straightforward as you can make it. Less is more...that's important" (parents2, lines 300-303).

\section{Discussion}

We used a qualitative method to answer the overarching research question, What preferences, if any, do teachers, education administrators, and parents have for graphically-displayed data? Next, we discuss the findings relative to the preferences identified and the factors that contributed to the preferences, followed by the study limitations. We conclude with implications for practice and further research.

\subsection{Preferences}

All three audiences expressed a clear preference for grouped columns over either stacked columns or bars, or the grouped bar graphs. This preference was consistent across all educational audiences with one exception. When administrators were asked whether they preferred multiple pages of graphs - each page with a graph containing fewer categories, or a single page with a graph containing more categories - administrators wanted the single graph. For this group, a graph on one page, even with a more complicated graphic display, was more appealing than having multiple pages of less complicated graphic displays. This finding was surprising given that administrators, like teachers and parents, had acknowledged that they found stacked columns and bars confusing and difficult to understand.

\subsection{Factors Contributing to Preferences}

Multiple factors contributed to participants' stated preferences for one graphic display over another. These factors include ease of understanding information displayed in the graph, familiarity with the display, comfort, as well as speed and habit for administrators. Relative to ease, participants described how grouped columns enabled them to easily see patterns in the data; a finding consistent with other researchers who advocate for the use of graphic displays of data (Riggleman, 1936; Wainer, 1997). Grouped columns enabled participants to look across the categories and quickly determine which category had higher or lower percentages. 
Being familiar with the data display contributed to the preference of all three audiences. Our findings are consistent with Henry (1993) who found educational audiences preferred data in a table over data displayed in two unfamiliar, new graphic formats (i.e., a multivariate 'star' graph and a univariate box plot). According to teachers and parents, their familiarity with the grouped columns contributed to their ability to see patterns in the data. Teachers and parents also frequently associated familiarity with both ease and comfort, describing how they were comfortable interpreting graphs and could easily see patterns because they were familiar with a particular graph. Parents explained that they were familiar with grouped columns from their days of being a student and from seeing simple column graphs routinely in their daily lives. For some parents, being familiar with the data display contributed to their willingness to look at the data and try to understand the information being conveyed. These few parents were adamant that they would not waste time trying to figure out the meaning of data in a stacked column graph. Parents' membership on educational stakeholder groups should be meaningful; the way data are presented graphically should not deter their participation in conversations about data use.

Comfort was another descriptor frequently used by teachers' and administrators' to describe their preference for one graphic display over another. What contributed to their comfort with a particular graph is not clear, as a reference to ease or comfort frequently included a reference to the speed or how quickly they could extract information or find meaning in a graph. It is possible that comfort, being a synonym for ease, was used interchangeably by these groups with no relevant difference. It is also possible that comfort is what results when a person is familiar with the data display, understands the information being conveyed, and feels they can easily and quickly make meaning from the data. Further exploration is needed to clarify and distinguish these meanings.

Finally, for administrators, two additional factors - habit and speed - contributed to their preferences for a particular graph. With regard to habit, at least a couple of state and district level administrators admitted during the focus groups that they had a habit of using the same graph format without giving thought to the task they wanted the audience to perform or whether the graph would contribute to or hinder an audience's understanding of information. This sentiment was not universal and should be further explored to determine prevalence, as at least one state level administrator disagreed with her colleague's assertion that selecting a graph format was habitual.

Administrators also repeatedly commented on the need to quickly obtain information from a graph. This factor contributed to both their preference for viewing a graph, that is, how quickly they could extract information, as well as how quickly an audience could extract information from a graph when presented. Administrators estimated they would spend a couple of minutes on a grouped column graph, whereas a stacked column may take up to 10 minutes; time they did not feel they had available for viewing graphs.

\subsection{Study Limitations}

Due to the research design, no causal inferences can be drawn between stakeholder preferences and their use of certain graphical/visual data displays. Given the purposeful sampling used to recruit, it is unlikely that participants are a representative sample of the three key educational stakeholder groups. Therefore, the overall generalizability of the findings is limited.

\subsection{Implications of the Study}

\subsubsection{Implications for Practice}

Using data to improve educational outcomes requires stakeholders to understand data and be comfortable discussing and interpreting information presented in graphs. To aid conversations about data, we recommend those responsible for creating and disseminating data graphically consider the following when creating a graph: (a) know the audience, (b) define the task, and (c) provide learning opportunities. Each recommendation is discussed briefly.

\subsubsection{Know the Audience}

By knowing the intended audience, designers of graphs can tailor how information is presented to better meet the audience's preferences, knowledge, and experience. For example, based on the findings of this study, grouped columns would be more appropriate for use by teachers and parents; stacked columns would be more appropriate for use by administrators. Tailoring the type of display used with each audience would seem to facilitate their comfort with viewing data, their willingness to invest time viewing data, and their understanding of what information is represented. These factors are critical if teachers, administrators, and parents are to actively and equally participate in data-driven decision making.

\subsubsection{Define the Task}

Defining what the audience is expected to do with the information, such as reading a single point, comparing categories, or identifying trends in a data display, is critical for audience involvement in data-based conversations. Not all data displays serve all purposes (Schmidt, 1983). Stacked column graphs have the advantage of displaying a great deal of 
information is a small space. However, as heard from our focus-group participants, extracting information from stacked columns can be difficult. At the state level, program specialists who know program content, and data managers who know data and presumably optional data displays, together play a crucial role in making data accessible and useable to diverse audiences. Together these two experts in their respective fields should determine the task to be performed and identify the type of data display that will facilitate the successful completion of that task. For example, teachers and parents in our focus groups acknowledged only looking at the overall percentage represented in the stacked column graph rather than the individual segments. If the desired task is to compare outcomes achieved by one category to another category, a grouped column graph facilitated that task more easily than the stacked column graph.

\subsubsection{Provide Learning Opportunities}

Several researchers (Ingram, Louis, \& Schroeder, 2004; Kerr, Marsh, Ikemoto, Darilek, \& Barney, 2006) advocate professional development specifically designed to develop graphicacy and other skills needed for data-based decision making. Parents in this study, consistent with Johnson's (2000) findings, expressed a desire to have the data explained to them and they wanted time to study the information. District administrators in our study expected to spend only a minute, no more than a couple of minutes, per graph and estimated that extracting information from stacked column graphs would take considerably longer; time they do not have available during a presentation. Strategies such as distributing sample graphs with key graphical elements highlighted for the audience prior to a meeting, or beginning a presentation with an explanation the type of graphs used in the discussion and materials could help audiences develop, or recall, basic graphicacy skills, facilitate their familiarity with the data display, and increase their comfort when viewing data.

\subsubsection{Implications for Research}

Our study was the first to explicitly investigate the preferences three key educational audiences - teachers, administrators, and parents - have for visually displayed data. This topic needs to be explored further to identify the relationships between preferences and factors that influence preferences, including what influence graph characteristics (e.g., color, tic marks) have on preferences. Further research should use authentic state data displays to determine whether participants identify the same preferences identified in this study. Finally, research is needed to examine the relationship between display type and stakeholders' accuracy of data interpretations.

\section{Conclusion}

Data are powerful agents of change and should be the basis for making important, programmatic modifications. Diverse audiences of stakeholders need to be comfortable engaging in conversations about data when using data for decision making. Graphs can facilitate stakeholders' participation in decision making processes if graph designers consider certain elements - audience, task, and preferences of the audience - when developing graphs. Considered collectively, these elements contribute to data displays tailored to meet the preferences of diverse educational audiences, which in turns leads to stakeholders using data to drive conversations.

\section{References}

Carnine, D. W. (Ed.). (1997). Bridging the research-to-practice gap. Mahwah, NJ: LEA Publishers.

Earl, L. M., \& Katz, S. (2006). Leading schools in a data-rich world: Harnessing data for school improvement. Thousand Oaks, CA: Corwin Press.

Friel, S. N., \& Bright, G. W. (1996). Building a theory of graphicacy: How do students read graphs? Annual Meeting of the American Educational Research Association. New York, NY.

Friel, S. N., Curcio, F. R., \& Bright, G. W. (2001). Making sense of graphs: Critical factors influencing comprehension and instructional implications. Journal for Research in Mathematics Education, 32(2), 124-158. http://dx.doi.org/10.2307/749671.

Hambleton, R. K., \& Slater, S. (1994). Using performance standards to report national and state assessment data: Are the reports understandable and how can they be improved? Joint Conference on Standard Setting for Large-Scale Assessments. Washington, DC.

Hambleton, R. K., \& Slater, S. (1996, April 9 -11, 1996). Are NAEP executive summary reports understandable to policy makers and educators? Paper presented at the Annual Meeting of the National Council on Measurement in Education, New York, NY.

Henry, G. T. (1993). Using graphical displays for evaluation data. Evaluation Review, 17(60), 60-78. http://dx.doi.org/10.1177/0193841X9301700105. 
Henry, G. T. (Ed.). (1997). Creating effective graphs: Solutions for a variety of evaluation data (Vol. 73). San Francisco, CA: Jossey-Bass Publishers.

Ingram, D., Louis, K. S., \& Schroeder, R. G. (2004). Accountability policies and teacher decision making: Barriers to the use of data to improve practice. Teachers College Record, 106(6), 1258-1287. http://dx.doi.org/10.1111/j.1467-9620.2004.00379.x

Johnson, C. E. (2000). Using post-school status data for special education graduates for program decisions. Seattle: University of Washington.

Kerr, K. A., Marsh, J. A., Ikemoto, G. S., Darilek, H., \& Barney, H. (2006). Strategies to promote data use for instructional improvement: Actions, outcomes and lessons from three urban districts. American Journal of Education (special issue), 112(August 2006), 496-520. http://dx.doi.org/10.1086/505057

Kowalski, T. J., \& Lasley, T. J. (editors). (2009). Handbook of data-based decision making in education. New York: Routledge.

McClure, G. B. (1998). The effects of spatial and verbal ability on graph use. Unpublished Dissertation, Albuquerque, NM: University of New Mexico.

Miles, M. B., \& Huberman, M. A. (1994). Qualitative data analysis. Thousand Oaks, CA: Sage Publications.

N6 qualitative data analysis software; QSR International Pty Ltd. Version 6, 2002.

Riggleman, J. R. (1936). Graphic methods for presenting business statistics. New York: McGraw-Hill Book Company, Inc.

Schmid, C. F. (1954). Handbook of graphic presentation. New York: Ronald Press Company.

Schmid, C. F. (1983). Statistical graphics: Design principles and practices. New York, NY: John Wiley \& Son, Inc.

Shah, P., \& Hoeffner, J. (2002). Review of graph comprehension research: Implications for instruction. Educational Psychology Review, 14(1), 47-69 http://dx.doi.org/10.1023/A:1013180410169.

Wainer, H. (1980). A test of graphicacy in children. Applied Psychological Measurement, 4(3), 331-340. http://dx.doi.org/10.1177/014662168000400305

Wainer, H. (1984). How to display data badly. The American Statistician, 38(2), 137-147. http://dx.doi.org/10.2307/2683253

Wainer, H. (1996). Using trilinear plots for NAEP state data. Journal of Educational Measurement, 33(1), 41-55. http://dx.doi.org/10.1111/j.1745-3984.1996.tb00478.x

Wainer, H. (1997a). Improving tabular displays, with NAEP tables as examples and inspirations. Journal of Educational and Behavioral Statistics, 22(1), 1-30. http://dx.doi.org/10.2307/1165236

Wainer, H. (1997b). Some multivariate displays for NAEP results. Psychological Methods, 2(1), 34-63. http://dx.doi.org/10.1037//1082-989X.2.1.34

Wainer, H. (1997c). Visual revelations: Graphical tales of fate and deception from Napoleon Bonaparte to Ross Perot. New York: Copernicus.

Wainer, H., Hambleton, R. K., \& Meara, K. (1999). Alternative displays for communicating NAEP results: A redesign and validity study. Journal of Educational Measurement, 36(4), 301-335. http://dx.doi.org/10.1111/j.1745-3984.1999.tb00559.x

Wayman, J. C. (2005). Involving teachers in data-driven decision making: Using computer data systems to support teacher inquiry and reflection. Journal of Education for Students Placed At-Risk, 10(3), 295-308. http://dx.doi.org/10.1207/s15327671espr1003_5

Wayman, J. C., \& Stringfield, S. (2006). Technology-supported involvement of entire faculties in examination of student data for instructional improvement. American Journal of Education (special issue), 112(August 2006), 546-468. http://dx.doi.org/10.1086/505059

Young, V. M. (2006). Teachers' use of data: loose coupling, agenda setting, and team norms. American Journal of Education (special issue), 112(August 2006), 521-547. http://dx.doi.org/10.1086/505058

\section{$(\mathrm{cc}) \mathrm{BY}$}

This work is licensed under a Creative Commons Attribution 3.0 License. 